\title{
STRATEGI PEMASARAN 7 P RESTORAN BERTEMA AUTENTIK DI BALE RAOS SEBAGAI POTENSI WISATA KULINER DI AREA KERATON YOGYAKARTA
}

\author{
Sahlit Sugesti \\ Sekolah Tinggi Pariwisata Ampta, Yogyakarta, Indonesia, sugestisahlit@gmail.com
}

\begin{abstract}
ABSTRAK
Histori Artikel

Indikasi keberhasilan pengelolaan wisata kuliner seperti restoran adalah banyaknya tamu yang datang ingin menikmati apa yang restoran tersebut tawarkan. Oleh sebab itu, diperlukan adanya strategi

Submitted:

4 Juli 2021

Reviewed:

4 Agustus 2021

Accepted:

8 Agustus 2021

Published:

15 November 2021 pemasaran yang tepat dan terarah. Penelitian ini bertujuan untuk menganalisis dan mendeskripsikan strategi pemasaran di Bale Raos sebagai restoran bertema autentik di kawasan wisata Keraton Yogyakarta. Penelitian menggunakan metode kualitatif. Informan yang dijadikan sampel adalah pihak managemen yaitu Direktur Utama (GM), Marketing, Manager Operasional, serta pengunjung yang datang. Pengumpulan data menggunakan wawancara, observasi, dan dokumentasi. Berdasarkan hasil penelitian menunjukkan strategi pemasaran yang tepat untuk meningkatkan kualitas mutu guna mempertahankan daur hidup perusahaan melalui segmentasi, penetapan sasaran yang tepat, dan penempatan produk dan disertakan kolaborasi antara strategi promosi harga, jenis wisata, lokasi, promosi, sumber daya manusia, proses dan bukti fisik.
\end{abstract}

Kata Kunci: potensi wisata, wisata kuliner, strategi pemasaran

\section{MARKETING STRATEGY 7 P AUTHENTIC THEMED RESTAURANT IN BALE RAOS AS A POTENTIAL OF CULINARY TOURISM IN KERATON OF YOGYAKARTA}

\begin{abstract}
Indications of successful management of cullinari such as a restaurant is a significant increase in the target number of tourists visiting. Therefore, it is necessary to have the right and targeted marketing strategy. This study aims to analyze and describe the marketing strategy of Bale Raos restaurant The autentic Taste in tourism area Keraton Yogyakarta. Research used qualitative methods. Informants sampled are general manager, marketing, operational manager and visitorAs of Bale Raos restaurant. Data was collected used interviews, observation, and documentation. Based on the research results show the right marketing strategy to increase quality product and service by segmenting targeting and positioning and collaboration of good product, price sale, place, promotion, people, process and physical evidance.
\end{abstract}

Keywords : potential tourism, culinary tourism, marketig strategy 


\section{PENDAHULUAN}

Memasarkan suatu produk dibidang kuliner memerlukan paket yang lengkap, dalam hal ini, makanan yang enak dan khas, tempat yang mudah di akses, dekat dengan daerah tujuan wisata, harga rasionable serta nuansa restoran/rumah makan yang menarik. Menurut Nugroho, 2014 mengatakan bahwa para pengunjung terkadang menikmati suatu makanan di salah satu tempat atau restoran bukan hanya sekedar ingin mengetahui atau menikmati makanannya saja melainkan juga menikmati suasana yang disajikan, baik dalam ornamen, letak atau nuansa juga diperhitungkan dalam mengambil keputusan pada saat ingin mengunjungi nya. Sebagian lagi para konsumen hanya ingin memunculkan prestige atau image saja yang ingin di tunjukan oleh orang lain, bahwa mereka sudah pernah mengunjungi tempat tersebut dan menikmati makanan tersebut. Makanan yang diburu biasanya makanan khas yang ada hanya di daerah tertentu, tidak disediakan di tempat lain. Begitu juga tempat serta nuansa yang di tawarkan, hanya berada di tempat itu saja. Tempat mempunyai disign etnik dan makanan bertema autentik.

Restoran yang ada di area wisata Keraton Yogyakarta mempunyai tema yang hampir sama yaitu bertema Keraton Yogyakarta, tema tersebut terlihat pada makanan yang di jual, lokasi dan bangunannya, salah satunya adalah Bale Raos yang berlokasi di kawasan Keraton Yogyakarta tepatnya di Jalan Magangan, nomor 1 Kecamatan Keraton Yogyakarta.

Selain makanan para pengunjung juga menikmati hidangan special, suasana Keraton masih sangat kental, Mulai dari bangunan yang ada, beberapa benda yang masih dipajang di beberapa pendopo hingga para Abdi Dalem yang berjaga di Regol belakang Keraton. Pengalaman semacam ini akan selalu menjadi kenangan yang tak terlupakan apabila wisatawan memutuskan akan menikmati hidangan di Restoran Bale Raos Yogyakarta.
Setiap restoran memiliki cara masing-masing dalam persaingan bisnis guna mempertahankan diri bagi kelangsungan daur hidup nya. Salah satu cara dalam persaingan guna mempertahankan diri, setiap restoron bisa menggunakan strategi pemasaran berupa $7 \mathrm{P}$ yaitu product, price, place, promotioan, people, proces dan physical efidence guna mengidentifikasi restoran tersebut kemudian diterpakan jurus andalan yang akan dilakukan sehingga tidak salah sasaran dalam mendatangkan pelanggan. Artikel ini menyajikan bahasan mengenai 1) Bagaimana konsep Segmenting, Targeting dan Positioning pada Restoran Bale Raos Yogyakarta sebagai Restoran bertema autentik. 2) Bagaimana pelaksanaan Strategi Pemasaran menggunakan Konsep Bauran Pemasaran (marketing mix) 7P (Product, Price, Place, Promotion, People, Proces dan Physical Evidence) yang dilakukan di Restoran Bale Raos sebagai Restoran yang bertema autentik.

Sedangkan tujuan dari penelitian ini adalah 1) Menganalisa konsep Segmenting, Targeting dan Positioning pada Restoran Bale Raos sebagai Restoran bertema Autentik. 2) Menganalisa Konsep Bauran Pemasaran 7 P (Product, Price, Place, Promotion, People, Proscess, Physical Evidance) di Restoran Bale Raos sebagai Restoran bertema Autentik.

\section{Konsep Strategi Pemasaran}

Dalam Swastha, 2008, William J. Stantom menyatakan bahwa pemasaran adalah suatu sistem keseluruhan dari kegiatan-kegiatan bisnis yang ditunjukan untuk merencanakan, menentukan harga, mempromosikan, dan mendistribusikan barang dan jasa yang memuaskan kebutuhan baik kepada pembeli yang ada maupun pembeli potensial. Sehingga dapat disimpulkan bahwa strategi pemasaran adalah suatu rencana yang diutamakan guna mencapai suatu tujuan dari kegiatan-kegiatan bisnis dalam merencanakan, menentukan harga, mempromosikan, dan mendistribusikan guna kepuasan kebutuhan konsumen.

Kotler (2012) menjelaskan ketika 
mengembangkan strategi untuk barang manufaktur, pemasar biasanya mengacu pada empat elemen dasar strategis yaitu produk (product), harga (price), lokasi atau distribusi (place), dan promosi atau komunikasi (promotion), sebagai sebuah kelompok, keempatnya biasanya disebut sebagai 4P dari bauran pemasaran (marketing mix). Perusahaan yang bergerak dalam bidang jasa terdapat tiga strategi tambahan pada strategi bauran pemasarannya yaitu orang (people), bukti fisik (physical evidence), dan proses (process). Oleh karena itu perlu diadopsi 7P sebagai penyesuaian terhadap lingkungan dan pelanggan dari organisasi jasa.

\section{Wisata Kuliner}

Menurut Asosiasi Pariwisata Kuliner Internasional (International Culinary Tourism Assosiation / ICTA) wisata kuliner merupakan kegiatan makan dan minum unik yang dilakukan oleh setiap pelancong yang sedang berwisata. Seorang peneliti Lucy Long dari Universitas Bowling Green di Ohio USA yang pertama kali mencetuskan kata-kata wisata kuliner di tahun 1998:

"Culinary tourism is defined as the persuit of unique and memorable culinary experience af all kinds, often while travelling, but one can also be a culinary tourist at home" (Long:1998).

Dapat di artikan bahwa wisata kuliner sebagai suatu pencarian tentang pengalaman kuliner yang unik dan selalu terkenang dengan beragam jenis, yang sering dinikmati dalam setiap perjalanan, tetapi bisa juga kita menjadi wisatawan kuliner dirumah sendiri.

\section{Restoran Bertema Autentik}

Restoran bertema autentik merupakan salah satu dari jenis special restoran, dan special restoran ini merupakan restoran yang memiliki karakteristik tersendiri, termasuk didalamnya suasana, interior, eksterior serta masakan yang disajikan lebih cenderung menonjolkan ciri khas suatu daerah atau negara dimana makanan tersebut berasal. Contohnya, Sundanese Restaurant, Javanese Restaurant, Chinese Restaurant, Italian Restaurant, Japanese Restaurant (Wiwoho,
2008).

Dalam Kamus Besar Bahasa Indonesia menyebutkan bahwa Autentik mempunyai arti dapat dipercaya, sah, asli, tulen. Sedangkan menurut English Oxford Living Dictionaries menyebutkan bahwa "Authentic Restaurant is a made or done in the traditional or original way, or in a way that faithfully resembles an original".

Sehingga bisa disimpulkan bahwa restoran autentik adalah suatu tempat yang menyediakan makanan dan minuman yang masih bersifat asli dan tradisional, baik dalam cara penyajian ataupun tempat itu sendiri.

\section{METODE}

Peneltiian telah dilakukan sebelumnya dengan pendekatan kualitatif. Dalam penelitian ini memiliki dua tahap yaitu tahap awal perencanaan penelitian yang terdiri dari identifikasi masalaha yang hendak di teliti, tempat penelitian, narasumber, dan teori kepustakaan yang ada. Sedangkan tahap kedua adalah pelaksanaan penelitian yang dapat dilihat dari observasi, wawancara, dokumentasi, pengolahan data lapanagan serta penarikan kesimpulan.

Peneliti mengacu pada teknik "purposive", dan peneliti memilih informan yang di anggap sebagai narasumber yang dapat dipercaya untuk menjadi sumber data yang mantap dan mengetahui masalahnya secara mendalam (Sutopo, 2006). Narasumber adalah Tim Manajemen dan Operasional restoran. Pengunjung juga menjadi salah satu informan dalam penelitian ini.

Teknik Pengumpulan data dalam penelitian ini menggunakan data primer dan sekunder. Data primer berasal dari sumber utama dan dikumpulkan secara khusus untuk menjawab pertanyaan penelitian, sedangkan data sekunder digunakan untuk mengisi kebutuhan akan rujukan khusus pada beberapa hal.

Teknik yang dipergunakan untuk mengumpulkan kedua jenis data tersebut yaitu teknik triangulasi. Teknik analisa data yang digunakan adalah analisis model 
interaktif (Interactive Model of Analysis) yaitu pengumpulan data, reduksi, penyajian data dan penarikan kesimpulan.

\section{HASIL DAN PEMBAHASAN}

\section{Bale Raos}

Restoran Bale Raos yang terletak di Jalan Magangan No. 1 Kecamatan Keraton Daerah Istimewa Yogyakarta. Pada awal restoran ini berdiri berfungsi sebagai penyedia layanan jasa makanan dan minuman yang diperuntukan hanya untuk acara di Keraton saja. Apabila Keraton terdapat acara seperti menjamu tamu baik dari Nusantara, Kenegaraan dan tamu dari luar negeri maka Restoran Bale Raos lah yang melayani perhelatan tersebut.

Seiring dengan hal pada tanggal 23 januari 2004 atas prakarsa KGPH Hadiwinoto, sebagai salah satu upaya merealisasikan gagasan dari GKR Hemas untuk melestarikan dan membuka pintu kepada masyarakat umum untuk bisa mengetahui dan menikmati aneka sajian kuliner yang berada di Keraton Yogyakarta maka Restoran Bale Raos resmi dibuka juga di tujukan untuk umum. Tujuan lain dibukanya restoran Bale Raos untuk umum adalah guna melestarikan kekayaan budaya yang salah satunya merupakan kekayaan kuliner asli dari Keraton, dari jaman tahta Sri Sultan yang terdahulu hingga sekarang, ditambah dengan sentuhan pengemasan yang lebih memikat sehingga dapat lebih diterima oleh masyarakat yang ingin mengetahui ragam masakan tersebut.

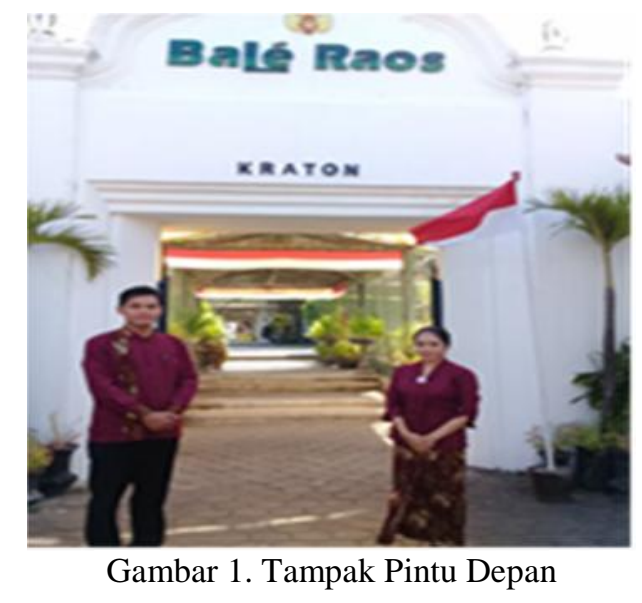

Konsep Strategi Pemasaran Segmenting, Targeting, Positioning pada Restoran Bale Raos

Dalam segmentasi geografis ditemukan bahwa pengunjung yang datang sebagian besar adalah dari luar kota Yogyakarta, sebagian besar dari kota Jakarta, Bandung yaitu sekitar $50 \%$ dan beberapa kota besar lainnya di Indonesia, sedangkan untuk wisatawan asing berkisar kurang lebih $30 \%$ serta sisanya $20 \%$ merupakan tamu lokal dari dalam kota.

Dalam segmentasi demografis ditemukan bahwa pengunjung yang datang ke restoran Bale Raos dari segala usia mulai anak-anak hingga dewasa (antara 5 - 65 tahun), baik pria maupun wanita. Berprofesi sebagai mahasiswa, karyawan swasta, ibu rumah tangga hingga pensiunan dan wisatawan asing serta ada yang sudah menikah dan masih lajang.

Dalam segmentasi psikografis ditemukan bahwa pengunjung datang ke restoran Bale Raos mulai dari yang sendiri, berpasangan, keluarga, rombongan kecil hingga rombongan besar (group). Sisi perilaku didalam pengunjung ditemukan bahwa ada yang baru pertama kali mencoba, lebih dari dua kali dan bahkan sudah ada pelanggan yang memang setia dengan restoran Bale Raos, untuk manfaat cenderung yang pertama kali lebih ingin mengetahui lebih dalam seperti apa tempat, suasana serta makanan yang disajikan, sedangkan bagi tamu yang lebih dari dua kali kecenderungan mengantarkan teman yang ingin mengetahui tentang Bale Raos, disamping memang tamu tersebut merekomendasikan untuk mencoba, sedangkan bagi pelanggan setia memang sudah percaya akan kualitas restoran tersebut, sehingga dalam menjamu tamunya serta beberapa acara mereka melakukannya di restoran Bale Raos, seperti acara wedding dan meeting.

Penjelasan tersebut diatas sesuai dengan pernyataan Kotler yang membedakan segmentasi pasar menjadi beberapa variabel, Bale Raos lebih cenderung memfokuskan pada wisatawan yang datang ke kota 
Yogyakarta, dengan pengunjung dari anak hingga dewasa, berusia antara umur 5-65 tahun. Lebih banyak tamu keluarga antara 410 orang hingga rombongan besar, antar 25100 orang. Pengunjung yang hanya berpasangan juga ada tetapi tidak begitu mendominasi. Mereka membidik atau menargetkan lebih cenderung ke kelas menengah keatas, walaupun tidak menutup untuk kalangan menengah kebawah untuk datang ke restoran Bale Raos.

Konsep Bauran Pemasaran (marketing mix) 7P (Product, Price, Place, Promotion, People, Proces dan Physical Evidance) yang di lakukan oleh Restoran Bale Raos.

Bauran Pemasaran atau Marketing mix merupakan seperangkat alat yang dapat digunakan pemasar untuk membentuk karakteristik jasa yang ditawarkan kepada pelanggan (dalam Tjiptono, 1997:6).

Kotler (2012: 62) menjelaskan ketika mengembangkan strategi untuk barang manufaktur, pemasar biasanya mengacu pada empat elemen dasar strategis yaitu produk (product), harga (price), lokasi (place), dan promosi (promotion), sebagai sebuah kelompok, keempatnya biasanya disebut sebagai 4P dari bauran pemasaran (marketing mix).

Perusahaan yang bergerak dalam bidang jasa terdapat tiga strategi tambahan pada strategi bauran pemasarannya yaitu orang (people), bukti fisik (physical evidence), dan proses (process) atau 7P.

Berikut ini uraian tentang bauran pemasaran (marketing mix) yang dilakukan oleh Restoran Bale Raos :

Produk (product): Bale Raos menyediakan produk yang beda dengan restoran lainnya yang cenderung menyediakan masakan modern ataupun masakan jenis special tertentu saja saja seperti special ikan, ayam atau daging, tetapi mereka menyediakan masakan makanan kegemaran para raja di Keraton Yogyakarta, setiap makanan tersebut memiliki cerita dan sejarah, ini lah yang menjadi unik dari makanan yang di tawarkan. Mulai dari makanan pembuka, soup, makanan utama, makanan penutup, kudapan sampai minuman. Hal ini sesuai dengan teori yang di sampaikan oleh Fandy Tjiptono yaitu produk yang banyak dicari, di beli dan dikonsumsi oleh seorang konsumen. Walaupun di restoran lain ada beberapa produk yang sama, tetapi yang pasti resep dari makanan-makanan kegemaran raja yang autentik hanya di Bale Raos.

Restoran ini tetap mempertahankan cita rasa asli dari resep yang telah turun temurun, dengan ditambahkan beberapa pemanis tamabhan seperti garnis agar makanan tersebut berpenampilan lebih menarik.

Harga (price): Harga yang ditetapkan oleh restoran Bale Raos merupakan formula dari standar recepi dan biaya lainnya yang mendukung terciptanya makanan tersebut, sedangkan pelayanan dan pajak belum termasuk didalamnya, sehingga pada saat pembayaran dikasir, tamu akan ditambahkan oleh biaya pelayanan dan pajak pemerintah sebesar $15 \%$, 5\% untuk pelayanan dan $10 \%$ untuk pajak pemerintah.

Harga terendah untuk makanan adalah kudapan berupa Manuk Nom dengan harga Rp. 12.500, sedangkan jenis makanan utama untuk harga paling tinggi adalah Bethak Ayam Set dengan harga Rp. 100.000. untuk harga paketan buffet paling rendah dengan harga Rp. 90.000 / px dan harga paling tinggi Rp. 165.000/px dengan full service style, harga paketan tersebut belum termasuk dengan biaya intertainment apabila tamu menghendaki bisa meriquest kepada marketing, mulai dari uyon-uyon, gamelan lengkap, pethilan tarian ramayana atau eloctone dan lain sebagainya. Untuk minuman paling tinggi adalah beer djawa dengan harga Rp. 30.000.

Lokasi (place): Lokasi sebaiknya tempat yang mudah untuk di lihat, tetapi untuk restoran ini tidak demikian, walaupun mudah untuk di akses, berada di kawasan wisata tetapi tempat cukup tersembunyi atau dengan kata lain tidak mudah dilihat oleh wisatawan, karena merupakan ikut didalam bangunan inti Keraton dimana dikelilingi oleh tembok yang tinggi dengan warna yang sama yaitu 
warna putih, baru setelah memasuki area parkir pengunjung akan mendapati tulisan didepan gerbang yaitu Restoran Bale Raos. Tetapi hal ini lah yang menjadi keunikan restoran tersebut.

Promosi (promotion): Restoran Bale Raos hanya melakukan untuk promosi yang berada dimedia sosial atau internet saja, hal ini banyak ditemukan dibeberapa link seperti seperti https://www.alamatjogja.com/baleraos-d-75/, kemudian terlihat juga di travel.tribunnews.com>bale-raos pada hari Rabu, 14 Maret 2018 pukul 13:27, yang bertajuk "Bale Raos, Restoran Unik di Jogja yang Punya Masakan Lezat Bercita Rasa Raja-raja Yogyakarta".

Bale Raos juga memiliki web sendiri dengan alamat www.baleraos.go.id disana setiap orang dapat melihat letak, bangunan, ornamen, makanan special, eventyang diadakan hingga testimonial dari tamu yang sudah pernah berkunjung. Tetapi untuk papan petunjuk atao baliho Bale Raos hanya menyediakan satu saja yaitu berada di depan J1. Magangan Kulon, yaitu pertigaan antara Jl. Ngadisuryan dan Pasar Ngasem. Hal ini kadang menyulitkan pengunjung yang berasal dari luar kota yang ingin mengujungi restoran Bale Raos.

Sumber Daya Manusia (people): Untuk Sumber Daya Manusia di restoran Bale Raos itu sendiri yang berhadapan dengan tamu langsung merupakan orang linier yaitu orang yang lulus dari sekolah mempunyai bidang pekerjaan dengan jurusan yang telah di ambil. Untuk staf service berasal dari lulusan SMK Perhotelan, sehingga mereka mempunyai dasar dalam menjalankan pekerjaannya, sedangkan untuk crew product awal hanya merupakan orang biasa yang di didik menguasai teknik masak serta mampu membuat masakan yang sesuai dengan resep yang telah ditetapkan, hal ini dimaksudkan, karena produk yang mereka hasilkan bukan dari makanan yang moderen, melainkan masakan khas Keraton yang membutuhkan ketelatenan untuk mempelajarinya.

Proses (process): Dalam proses para staf melakukan job Describtion sesuai dengan
SOP yang telah ditetapkan oleh masingmasing bagian di Restoran dengan baik dan benar, terkadang tidak semua proses dilakukan secara berurutan sesuai dengan SOP dikarenakan situasi dan kondisi pada saat restoran dalam keadaan ramai, sehingga para karyawan harus dapat membelah fokus di antara banyak tamu yang datang.

Bukti Fisik (Physical Evidence): Restoran Bale Raos memiliki sesuatu yang spesial dimana setiap inci sudut restoran merupakan tempat yang special, yang menjadi andalan adalah restoran ini merupakan satu wilayah dengan Keraton bagian belakang.

\section{SIMPULAN}

Berdasarkan hasil penelitian dan pembahasan, penelitian tentang strategi pemasaran untuk peningkatan jumlah pengunjung di Restoran Bale Raos dapat disimpulkan bahwa:

\section{Strategi Pemasaran Segmenting, Targeting, Positioning}

Berdasarkan hasil penelitian, diketahui bahwa restoran Bale Raos mempunyai segmentasi pasar wisatawan luar kota, perusahaan swasta dan instansi pemerintah, lebih membidik ke kalangan menengah keatas, walaupun tidak menutup kemungkinan dari kalangan selain itu untuk datang ke restoran, sebagian kecil wisatawan asing dan sisanya adalah pengunjung dari kota Yogya itu sendiri.

Untuk mempertahankan bisnis dengan persaingan sejenis restoran Bale Raos hanya melakukan hal yang sewajarnya, yaitu mempertahankan kualitas mutu dan produk yang dihasilkan, baik berupa produk nyata (tangible) maupun tidak nyata (intangible), seperti makanan / minuman serta pelayanan.

Bauran Pemasaran (marketing mix) 7P, Product, Price, Place, Promotion, People, Process, Physical Evidance

Produk (product): Pada restoran Bale Raos memiliki produk yang autentik, unik karena hanya ada di Restoran ini saja, walaupun di restoran lain ada beberapa menu yang sama 
tetapi pihak Keraton hanya memberikan kuasanya untuk Bale Raos dapat memperkenalkan menu kegemaran raja kepada masyarakat, menu yang mempunyai cerita dan cita rasa yang sangat mengagumkan. Itulah mengapa Restoran Bale Raos disebut sebagai Restoran bertema Autentik.

Harga (price): Dalam harga sebagian tamu merasa bahwa harga yang ditetapkan adalah rasionable atau dapat diterima, karena sebagian besar tamu yang datang merupakan tamu wisatawan dari luar kota khususnya Jakarta dan merupakan kalangan menengah keatas sehingga harga sudah sesuai dengan apa yang mereka terima.

Lokasi (place): Sangat spesial karena berada di dalam area Keraton, walaupun sedikit sulit untuk ditemukan karena tidak nampak oleh mata langsung dari jalan, mengingat berada di dalam area keraton yag di kelilingi tembok tinggi dan jalan yang beliku dari jalan utama.

Promosi (promotion): Untuk promosi guna mengenalkan produk serta tempat sudah dilakuka melalui media sosial, acara televisi tentang liputan kuliner serta media cetak baik dalam maupun luar negeri. Tetapi untuk papan petunjuk dan baliho promosi hanya mempunyai satu di depan jalan restoran Bale Raos, sehingga bagi pelanggan yang datang pertama kali sedikit sulit untuk menemukan restoran Bale Raos.

Sumber Daya Manusia (people): Sumber Daya Manausia yang bekerja di restoran Bale Raos hampir keseluruhan menguasai bidang pekerjaan masing-masing sesuai job describtion yang telah ditetapkan oleh pihak managemen berdasarkan SOP yang ada.

Proses (process): Karena staf menguasai Job describtion masing-masing bagian maka meraka dapat melakukan proses secara baik, hal ini terkadang tidak dilakukan sesuai prosedur apabila restoran dalam keadaan ramai.

Bukti Fisik (Physical Evidence): Tata bangunan dan beberapa ornamen ditambah suasana membuat restoran Bale Raos lebih unggul dibanding restoran lain, memngingat restoran ini berada di kawasan Area Keraton. Sehingga membuat nilai plus dibanding restoran lain disekitarnya.

\section{REFERENSI}

Fandy. (1997). Strategi Pemasaran, Edisi Kedua. Yogyakarta: Andy

Kotler, P. (1992). Manajemen Pemasaran

(Analisis, Perencanaan dan

Pengendalian). Edisi Kelima. Jilid I. Jakarta: Erlangga.

Kotler, P. (1996). Manajamen Pemasaran (Analisis Perencanaan Pengendalian). Terjemahan Drs. Jaja Wasana MSM. Institut \& Pembinaan Manajemen, Jilid I, Edisi Kelima, Cetakan Ketujuh. Jakarta: Erlangga.

Kotler, P. (2005). Manajamen Pemasaran. Jakarta: PT. Indeks. Kelompok Gramedia.

Kotler, P\& Keller, KL. (2007). Manajemen Pemasaran, Edisi Bahasa Indonesia. Jakarta: PT Indeks

Kotler, P\& Keller, K L. (2009a). Manajemen Pemasaran, Edisi Ketiga Belas Jilid 1. Jakarta: Erlangga.

Kotler, P \& Keller, K.L. (2009b). Manajemen Pemasaran, Edisi Ketiga Belas Jilid 2. Jakarta: Erlangga.

Lovelock, Christopher, H \& Wright, Lauren, K. (2007). Manajemen Pemasaran Jasa. Edisi Bahasa Indonesia. Jakarta: PT Indeks

Moleong, L.Y. (2009). Metodologi Penelitian Kualitatif (Edisi Revisi). Bandung: PT. Remaja Rosdakarya.

Nugroho, S. P. (2014). Kualitas Pelayanan Gadri Resto Yogyakarta (Respon Konsumen sebagai Pendekatan Penelitian). Jurnal Nasional 
Pariwisata, 6(1), 22-29.

Oka, I Made Darma. (2010). Potensi Pengembangan Pariwisata Minat Khusus (Trekking) Di Desa PejatenTabanan. Jurnal Analisis Pariwisata, 10 (1), 24-31.

Wiwoho, Ardjuno. (2008). Pengetahuan Tata Hidang. Jakarta: Erlangga.

WA, Marsum. (1994). Restoran dan Segala Permasalahannya, Edisi Kedua, Cetakan Pertama. Yogyakarta: Andy Offset.

Yoeti, Oka A, Drs, MBA. (1996). Pengantar Ilmu Pariwisata. Jakarta: Percetakan Angkasa.

Yoeti, Oka A, Drs, MBA. (2001). Ilmu Pariwisata Sejarah, Perkembangan, dan Prospeknya. Jakarta: PT. PERTJA.

Webster's Encyclopedic Unabridged Dictionary of the English Language. (1989). New York: Portland House.

http://www.Pariwisata Menurut Ahli.co.id

UU No. 10 thn. 2009. Tentang

Kepariwisataan.

Peraturan Pemerintah No. 24/1979. Tentang Daerah Tujuan Wisata.

Surat Keputusan Departemen Pariwisata, Pos, dan Telekomunikasi No. KM 98/PW:102/MPPT-87. Tentang DTW.

Peraturan Menteri Pariwisata dan Ekonomi Kreatif No. 4. Tahun 2021. Tentang Standar Kegiatan Uasaha Pada Penyelenggaraan Perizinan Berusaha Berbasis Risiko Sektor Pariwisata.

\section{BIODATA PENULIS}

Sahlit Sugesti, adalah Dosen Tetap pada Program Studi Pengelolaan Perhotelan, Sekolah Tinggi Pariwisata AMPTA Yogyakarta. Memiliki kepakaran dibidang food and beverage service. Mengajar Praktek Tata Hidang Praktek dan Peralatan Boga dan Restoran. 